\title{
Chapter 2 \\ Technology Transfer and Agricultural \\ Development: A Comparative Study \\ of Asia and Africa
}

\author{
Keijiro Otsuka
}

\subsection{Introduction}

A few centuries ago, Malthus predicted that famine will inevitably take place because, while the population grows exponentially, food production increases only arithmetically. Following the Malthusian argument, the Club of Rome predicted in the early 1970s that famine cannot be avoided in tropical Asia (Meadows et al. 1972). ${ }^{1}$ However, serious famine has never taken place in this region for the past half century and, hence, Malthus' prediction may appear questionable. However, by reviewing the history of growth of population and food production, his prediction turns out to be almost correct (Otsuka 2013). What he failed to predict was the technological change induced by population pressure (Hayami and Ruttan 1985), which resulted in the rapid growth of food production, thereby restoring or more than restoring the balance between population and food production. In other words, the fear of Malthusian hardship, or severe food insecurity, begot efforts to overcome it by means of technological changes based on international technology transfer.

Indeed, the Green Revolution for rice as well as wheat, defined as the development and diffusion of high-yielding varieties, took place in tropical Asia in the 1970s and 1980s, when the population pressure on the limited land became severe enough (David and Otsuka 1994). However, the Green Revolution for major grains has failed to hitherto take place in sub-Saharan Africa (SSA), although current population pressure is as severe as in tropical Asia in the 1960s (Otsuka and Larson 2013, 2016). Unless a sufficient food supply is secured, the economy can unlikely evolve from a poor agrarian state to an emerging state with decent development of manufacturing industries and service sectors. Indeed, as agriculture is a dominant industry at the early

${ }^{1}$ Tropical Asia refers to Southeast and South Asia.

K. Otsuka $(\bowtie)$

Graduate School of Economics, Kobe University, Kobe, Hyogo, Japan

e-mail: otsuka@econ.kobe-u.ac.jp

K. Otsuka and K. Sugihara (eds.), Paths to the Emerging State in Asia and Africa,

Emerging-Economy State and International Policy Studies,

https://doi.org/10.1007/978-981-13-3131-2_2 
stages of economic development, its progress is a prerequisite for overall economic development.

The first major issue to be addressed in this chapter is identifying the conditions under which the Green Revolution successfully took place in Asia. For this purpose, I review the historical experiences of the prototype Green Revolutions in rice production in prewar Japan, Taiwan, and Korea, and tropical Asia in the 1970s and 1980s. I find that a major determinant of the Green Revolution was technology transfer. Indeed, Hayami and Godo (2005) argue, among others, ${ }^{2}$ that the essence of the Asian Green Revolution in rice was the transfer of intensive rice farming systems from Japan to tropical Asia, which is characterized by the adoption of fertilizer-responsive highyielding varieties, intensive use of commercial fertilizer, and application of improved management practices. While it is understandable that the transfer of technologies from a temperate zone, such as Japan, to tropical Asia would have been difficult because of the substantial climate differences, it is not easily understandable why it is so difficult to transfer technology from one tropical zone to another (i.e., from tropical Asia to SSA). An exploration into the causes for the failure of the Green Revolution in SSA is the second major issue to be addressed in this chapter.

However, agricultural development alone is not sufficient for the economy to evolve from an agrarian to an emerging state, as there are strong relationships between agricultural development and that of nonfarm sectors (e.g., supply of food and processing materials and labor from agriculture and demand for products and services provided by nonfarm sectors in rural areas). Therefore, to identify the significance of agricultural development, this chapter identified paths to the emerging state based on the analysis in this chapter and the companion studies on agricultural development and policies reported in Chaps. 10-12, as well as the industrial development policies in SSA discussed in Chap. 9.

The organization of this chapter is as follows. While Sect. 2.2 reviews the prototype Green Revolutions in rice farming in prewar Japan, Taiwan, and Korea, Sect. 2.3 assesses the Green Revolution in rice farming in Southeast and South Asia in the 1970s and 1980s. Section 2.4 examines the possibility of a Green Revolution in SSA, focusing on its constraints on this continent. Finally, Sect. 2.5 discusses the role of agricultural development in steering the economy towards an emerging state.

\subsection{Prototype Green Revolutions in Prewar Japan, Taiwan, and Korea}

There was a race between population growth and expansion of food production during the Meiji era (1868-1912) in Japan, principally because the country is characterized by meagre endowments of cultivable land relative to its population. In fact, the average farm size was merely one hectare. However, as shown in Fig. 2.1, grain

\footnotetext{
${ }^{2}$ Both agricultural economists (e.g., Dalrymple (1986) and Hsieh and Ruttan (1967)) and agricultural scientists (e.g., Tanaka (2012) and Tanaka and Imai (2006)) express similar views.
} 


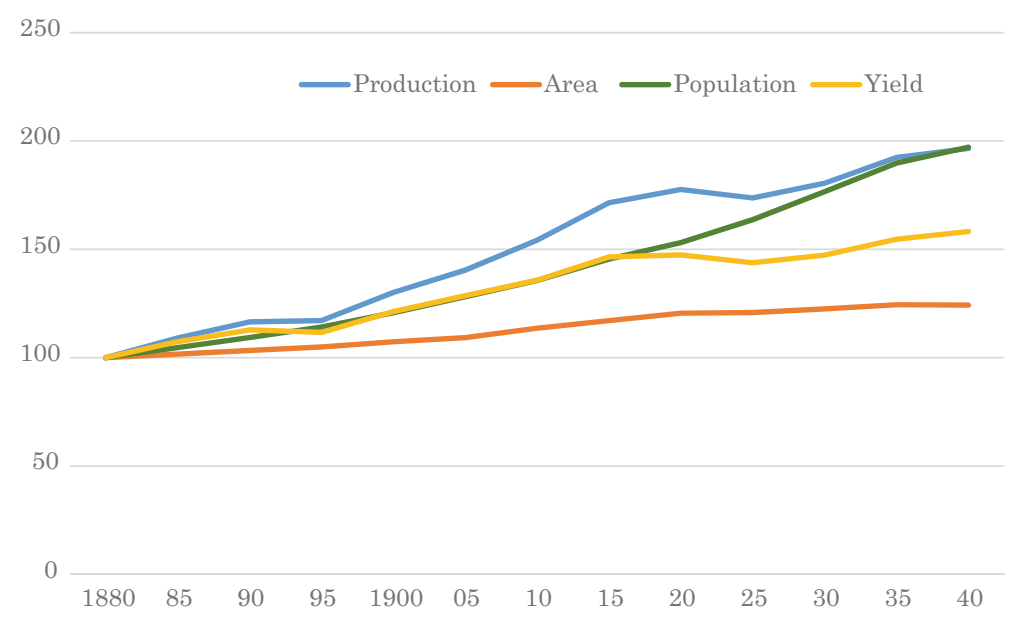

Fig. 2.1 Changes in grain production, cultivation area, population, and grain yield in Prewar Japan (Index: $1880=100$ ). Source Umemura et al. (1966)

production increased rapidly from 1880 to roughly 1915 due to the sustained increase in grain yield per hectare, although cultivation area increased slowly throughout the prewar period due to the limited availability of unused land. Suddenly, grain production and yield stopped increasing around 1915 and grain production per capita continued to decline thereafter, as population growth surpassed that of food production. Nonetheless, this increasing "food deficiency" did not induce grain yield growth in the subsequent prewar period in Japan. As a result, rice price increased, and the rice riot occurred in 1918, in which people violently attacked rice dealers who were suspected to control rice markets and increase rice prices. Since rice is a so-called wage good or the good on which urban households spend large proportions of their income, increases in its price tend to trigger not only social instability but also increase in wage cost, which is in turn detrimental to the development of industries and other nonfarm sectors.

Grain production and yield increased rapidly in the Meiji era primarily because of the rapidly increasing rice yield (see Fig. 2.2). ${ }^{3}$ According to Hayami and Godo (2005, p. 99), "[c]rop varieties similar to those of modern varieties were selected through trial and error by experienced farmers" before and during the Meiji era. While modern varieties (MVs) developed for tropical Asia since the late 1960s are semi-dwarf, possessing short stems, the improved varieties developed in Japan during

\footnotetext{
${ }^{3}$ Note that rice yield is measured as tons of brown rice per hectare in Fig. 2.1. On the other hand, in developing countries, it is measured in terms of tons of paddy rice. Since paddy is roughly $20 \%$ heavier than brown rice, rice yield in Japan at the beginning of Meiji era was estimated to be roughly 2.4 tons per hectare in terms of paddy.
} 
Fig. 2.2 Changes in rice yield per hectare in Prewar Japan, Taiwan, and Korea, and Postwar Philippines, Five-Year Moving averages (reproduced from Hayami and Godo 2005, p. 101)

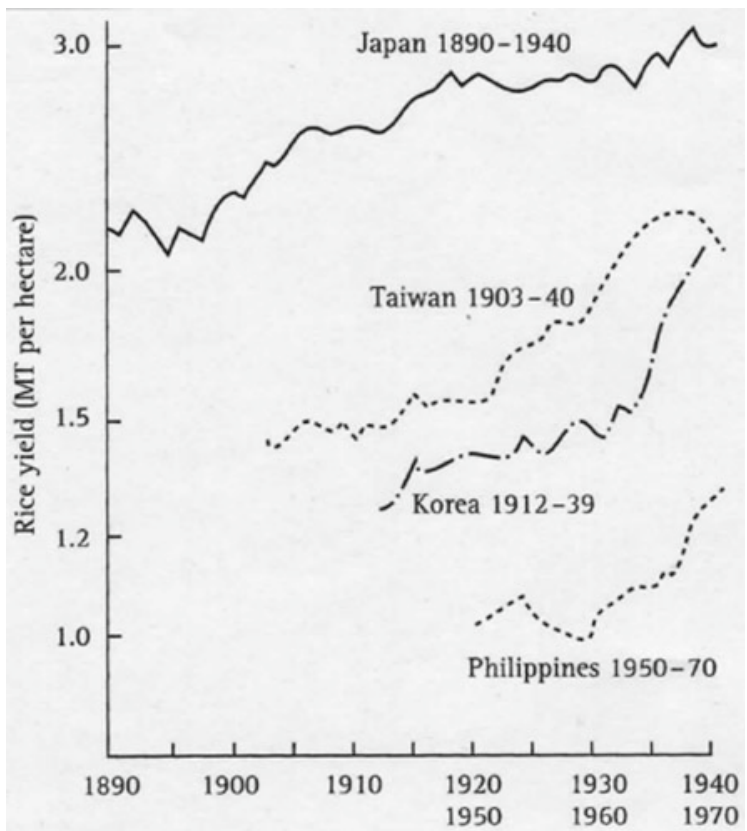

the Meiji period were not necessarily semi-dwarf. ${ }^{4}$ Similar to MVs, those improved rice varieties in Japan were resistant against lodging, so that a heavier application of fertilizers leads to higher yield. Such fertilizer-responsive varieties were initially selected in the western region and their diffusion boosted registered yield growth from 1895 to 1910. Such superior varieties in the western region served as parental varieties to developing improved varieties suitable for the ecologies of the eastern region by leading farmers and experiment-station workers. Consequently, yield growth took place five to ten years later in this region. However, once new varieties were completely diffused, yield became stagnant throughout Japan by the mid-1910s.

Facing the risk of high rice prices and drain on scarce foreign exchange by largescale rice imports, the Japanese government decided to increase rice production and imports from the overseas territories of Korea and Taiwan. Further, the government actively invested in irrigation and water control and in research and extension to develop and diffuse high-yielding Japanese varieties adapted to the local ecologies of Korea and Taiwan and transfer improved agronomic practices (Hayami and Ruttan 1985). As a result, fertilizer-responsive, high-yielding ponlai varieties were developed in Taiwan, which were cross-bred between Japonica and Indica rice varieties and also between improved Japonica varieties. Tanaka and Imai state (2006) that the expansion of rice production in Taiwan was made possible by the transfer of

\footnotetext{
${ }^{4}$ However, Dalrymple (1986) points out that the first efforts to develop semi-dwarf rice varieties occurred in Japan in the late 19th century, leading to the development of an improved variety called Shinriki.
} 
the Japanese farming system, based on improved seeds, application of fertilizer, and irrigation. Hayami and Ruttan (1985) conclude that "the economic implication of the ponlai varieties for Taiwan in the 1920s were essentially equivalent to those of the modern rice varieties in the tropics today." Similarly, Hsieh and Ruttan (1967) argue that new rice varieties now being developed in tropical Asia in the 1960s resemble, in terms of fertilizer responsiveness and yield potential, the ponlai varieties introduced to Taiwan in the mid-1920s.

As per Fig. 2.2, rice yield increased slowly during the 1910s and dramatically in the 1920s in Taiwan. This coincides with the development of ponlai varieties, the first one being Taiching 65, developed in 1924 from a cross of two Japanese varieties (Tanaka 2012). Rice production in Korea was less successful than in Taiwan because of the lower levels of irrigation and water control, but rice yield in this country nonetheless accelerated in the 1930s. ${ }^{6}$ The yield growth in both Taiwan and Korea was obviously the result of technology transfer from Japan, where adaptive agricultural research, irrigation investment, and technological extension played critical roles. A stable supply of rice to Japan from Taiwan and Korea undoubtedly contributed to rice price stability and increased its availability in Japan, thereby contributing to the sustainable growth of nonfarm sectors in prewar Japan.

\subsection{Green Revolution in Tropical Asia}

Not only the Club of Rome (Meadows et al. 1972) but also the majority of those interested in the development of agriculture in tropical Asia were worried about the future balance between rice supply and demand in the 1960s and early 1970s in this region, because population was increasing, rice yield had stagnated, and uncultivated land had been largely exhausted (Barker and Herdt 1985). As is shown in Fig. 2.3, population grew in parallel with grain production in the 1960s in Tropical Asia. However, grain production fluctuated widely, which means that food shortages took place occasionally during poor crop years (e.g., in 1965-1966 in West Bengal). Without exaggeration, it can be argued that tropical Asia was on the verge of famine due to increasing population pressure, as predicted by Malthus.

As per Fig. 2.3, grain production began increasing since the mid-1960s and its growth rate accelerated in the 1970s and 1980s, thereby surpassing the population growth by a wide margin. Grain production increased not because of the expansion of land area, but largely because of yield growth. This is a result of the Green Revolution, primarily for rice but also for wheat in tropical Asia.

For rice, the first semi-dwarf, fertilizer-responsive, high-yielding MV, IR8, was released in 1966 by the International Rice Research Institute (IRRI) in the Philippines, which was established in 1960 by support of the Rockefeller and Ford Founda-

\footnotetext{
${ }^{5}$ Dalrymple (1986) points out that early ponlai varieties were not semi-dwarfs.

${ }^{6}$ It is also worth noting that rice yield in Japan began increasing in the 1930s due to the lagged effect of establishing modern agricultural research and extension systems during the Meiji era.
} 


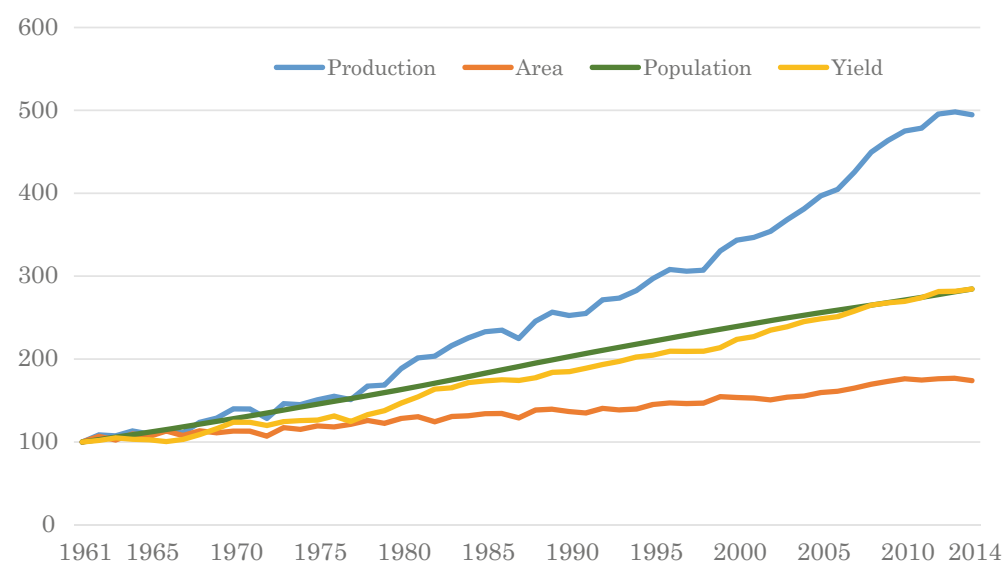

Fig. 2.3 Changes in grain production, harvested area, population, and grain yield in tropical Asia (Index: $1961=100)$. Source FAOSTAT (2016)

tions. ${ }^{7}$ IR8 was the result of a cross between Peta, a tall variety from Indonesia, and Dee-Geowoo-Gen, a semi-dwarf variety from Taiwan. Although the contribution of Japanese scientists to the development of Dee-Geowoo-Gen in Taiwan is not clear, the basic idea of Green Revolution is obviously the same as the growth of rice yield based on the development of high-yielding varieties in Japan during the Meiji era. Indeed, Hayami and Godo (2005, p. 97) point out that "IR8 was modeled after the high-yielding Japanese varieties." 8

The rice yield in Southeast Asia began increasing since 1966 and accelerated since the mid-1970s (Fig. 2.4). This is because IR8 and other early IRRI varieties were potentially high-yielding under favorable production environments but susceptible to pests and diseases, with major yield gains being achieved only after pest- and diseaseresistant varieties were developed in the mid-1970s (David and Otsuka 1994). As a result, paddy yields in Southeast Asia were only half of those in Northeast Asia in the 1960 s but increased to about two-thirds by the 2010s. ${ }^{9}$

It is remarkable that rice yield in South Asia began growing with a time lag of five to ten years compared with Southeast Asia. This is important because rice MVs were highly transferable from Southeast Asia to South Asia, not to mention from one

\footnotetext{
${ }^{7}$ For rice plant to be fertilizer responsive, it is desirable to be short and their stem thick. If the plant is fertilizer responsive, it is also high-yielding. Improved varieties used to be called "high-yielding varieties," but since they are not high-yielding in areas subject to drought and floods, they are now more commonly called "modern varieties".

${ }^{8}$ Japanese agricultural scientists made significant contributions to the development of IR8. IRRI also learned rice science from Japan by translating articles and books about rice from Japanese into English.

${ }^{9}$ Northeast Asia refers to Taiwan, South Korea, and Japan.
} 


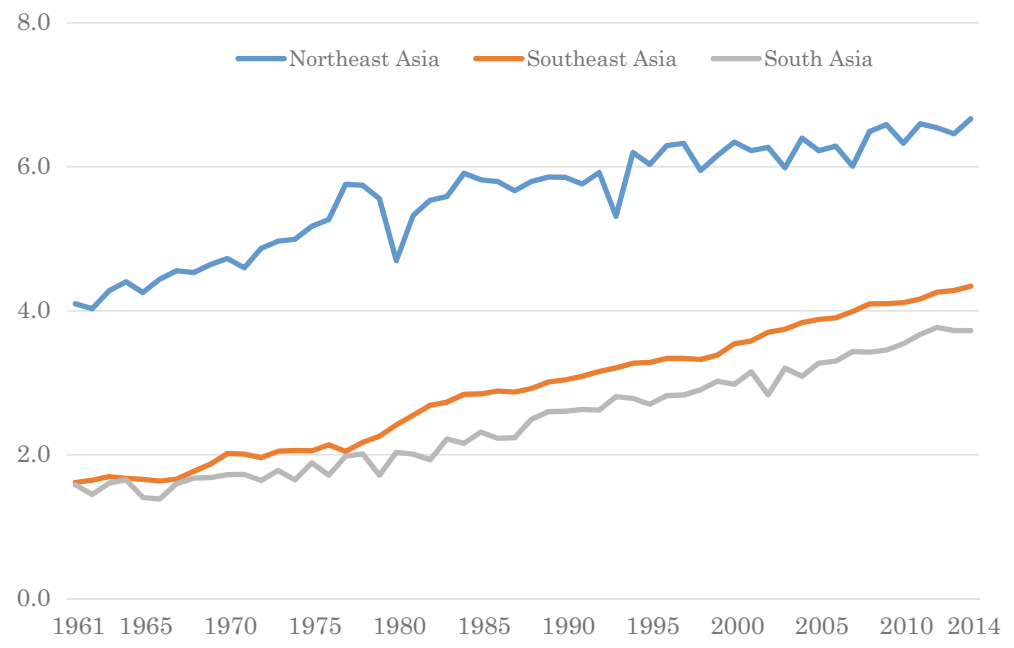

Fig. 2.4 Changes in rice yield in Northeast, Southeast, and South Asia. Source FAOSTAT (2016)

country to another within Southeast Asia. ${ }^{10}$ In fact, IR8 and related varieties were widely grown in India and Bangladesh, although these varieties were later replaced by newer ones, generated by cross-breeding between IRRI and local traditional varieties (Janaiah et al. 2005). Rice yield in South Asia has been lower than in Southeast Asia, primarily because of lower availability of irrigation in the former, which indicates the decisive importance of irrigation for high rice yields (see Chap. 12).

In this way, rice production technology in tropical Asia improved, which led to sustainable growth in rice production. The upper panel of Fig. 2.5 shows that global rice production continued to increase over the past several decades. Since more than 90 percent of rice is produced in Asia, the rice Green Revolution significantly contributed to increasing rice production globally. In other words, technology transfer from Japan to Taiwan and further from Taiwan to tropical Asia resulted in a significant growth in rice production (Tanaka 2012). As a result, real rice prices continued to decline due to increasing rice production, coupled with price- and income-inelastic demand for rice, until the "food crisis" in 2008. The real rice price around 2000 was merely one-third of the level around 1970. This sharp reduction in real rice prices indicated that the major beneficiaries of the Green Revolution were rice consumers, including urban workers, whereas rice farmers who failed to adopt improved technology due to unfavorable production environments lost because of lower rice prices (David and Otsuka 1994). On the other hand, rice farmers who adopted improved rice technologies received benefit from enhanced production efficiency but still suffered

\footnotetext{
${ }^{10}$ For example, IRRI varieties were widely diffused not only in the Philippines, but also in Indonesia and rice yield was higher in the latter than the former.
} 

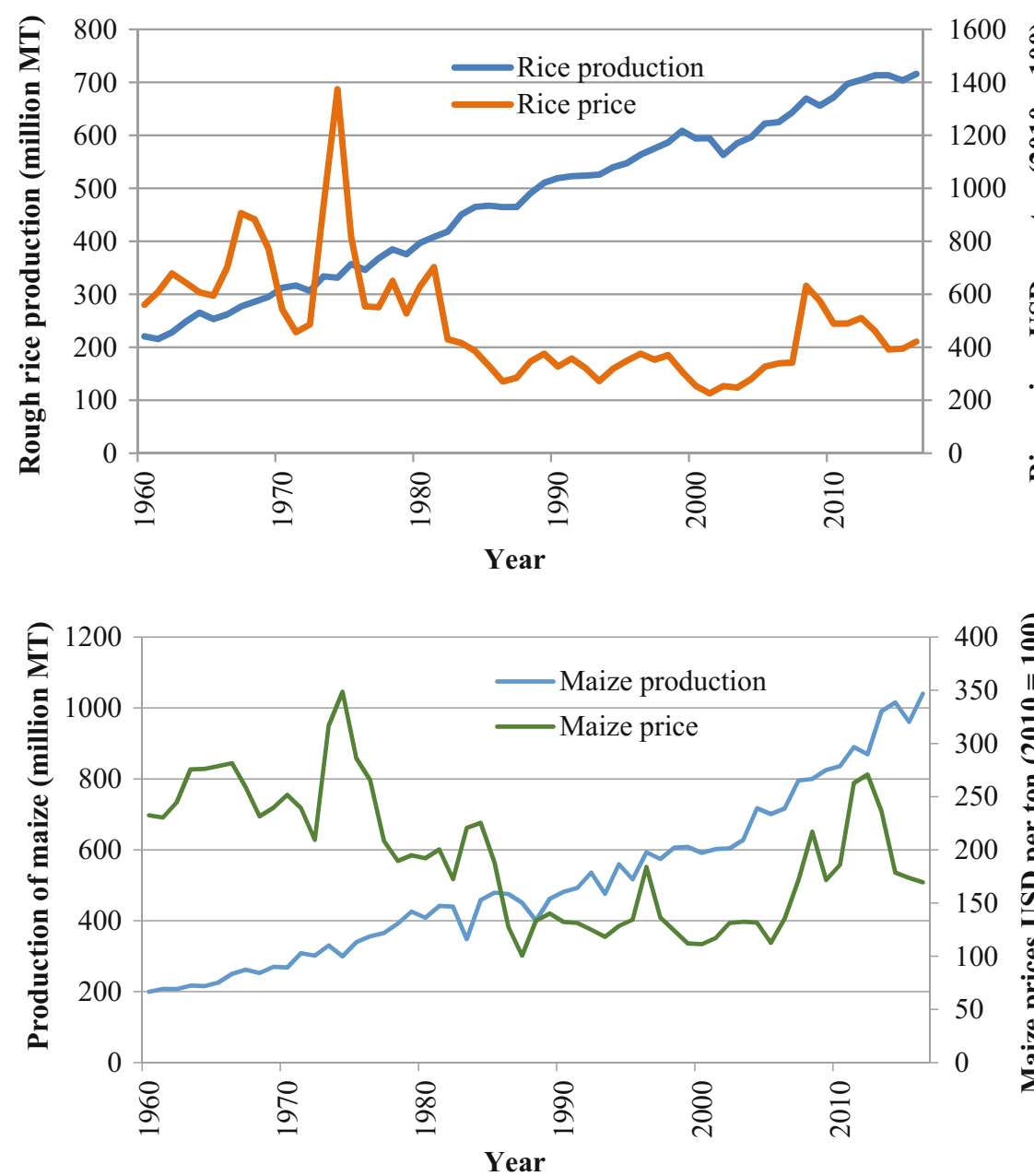

Fig. 2.5 World production and real prices for rice and maize, 1961-2016. Source United States Department of Agriculture database

from price reductions, ${ }^{11}$ with the net effect more likely to be rather negative because of the sharp rice price reduction. The lower panel of Fig. 2.5 indicates that not only the real price of rice but also that of maize had been declining from the 1960s to the middle of the first decade of this century, because of the increasing maize yield and production. ${ }^{12}$

\footnotetext{
${ }^{11}$ Although there are no official statistics on the adoption rates of MVs in tropical Asia, they are likely to be between 75 and $80 \%$ as of now.

${ }^{12}$ Grain prices fluctuated widely around 1974 and 2008, partly because of the slight shortfall in production, but more importantly because of excessive speculation.
} 
Although there is no direct evidence that the Green Revolution in tropical Asia contributed to building emerging states in this region, it would not be unrealistic to argue that a sufficient supply of such an important staple crop as rice contributed significantly to the stability of Asian societies by improving the well-being of rice consumers without excessively sacrificing the welfare of most rice farmers. Since rice is a wage good, the reduction in rice prices must have stimulated the development of industries and other nonfarm sectors by reducing the cost of living for urban workers. If there had been no Green Revolution, people in tropical Asia would have been adversely affected by the high rice prices, persistent food insecurity, and occasional famines in the worst-case scenario and the import of expensive grains from elsewhere in the world in the best-case scenario.

\subsection{Possibility of a Green Revolution in SSA}

Boserup (1965) argues that population pressure on limited land areas stimulates the spontaneous adoption of land-saving and labor-using production methods by farmers, which leads to an increase in crop yield. However, this view is not necessarily consistent with the reviewed historical experience. Even when population pressure increased in prewar Japan, rice yield did not increase without technological changes. Similarly, rice yield increased significantly in tropical Asia only after MVs were developed. Hayami and Ruttan (1985) argue that population pressure induces not only technological innovations but also institutional innovations, which supports the development and diffusion of innovations. As such, the Asian experience seems more consistent with this latter view than the Boserupian one.

Although there are a few land abundant countries in SSA, the ratio of arable land to rural population, on average, has been steadily declining (see Fig. 2.6). As a result, the land-population ratio in SSA now is similar to that in tropical Asia on the eve of the Green Revolution. However, since rainfall is lower in SSA, the quality-adjusted land-population ratio could be much lower than face value in SSA. Therefore, if the Hayami-Ruttan (1985) posited innovation hypothesis is relevant, it might be opportune for SSA to launch the Green Revolution.

From the trends of grain production, ${ }^{13}$ cultivation area, population, and grain yield in SSA, it is clear that while population has been growing continuously, the growth of grain production was much slower from 1961 to around 2000 (Fig. 2.7). This is similar to or worse than the situation in tropical Asia in the 1960s (see Fig. 2.3). The imbalance between the growth of population and grain production contributes to the food insecurity in SSA, particularly around the turn of the century, when the gap between the trends of population and grain production growth was maximum. However, it is remarkable that grain production growth became faster than population growth over the past one and a half decades. Grain production increased not only

\footnotetext{
${ }^{13}$ Grain includes maize, sorghum millet, rice, and wheat, and production is the total quantity of the grain production. Note that yams, cassava, and plantain are also important staple foods in SSA.
} 


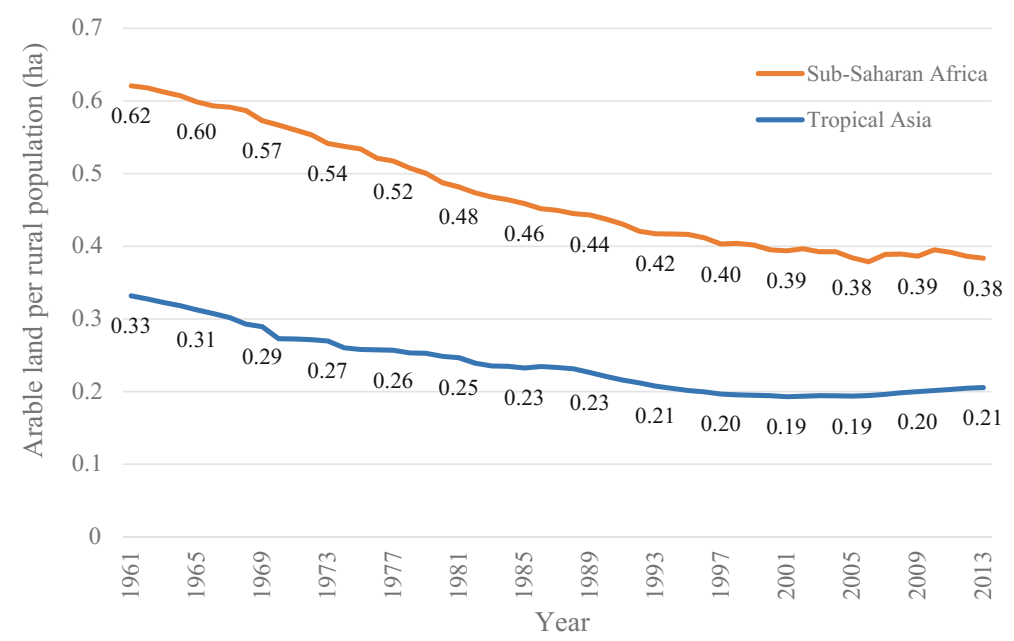

Fig. 2.6 Arable land per rural population in tropical Asia and SSA, 1961-2013. Source FAOSTAT (2016)

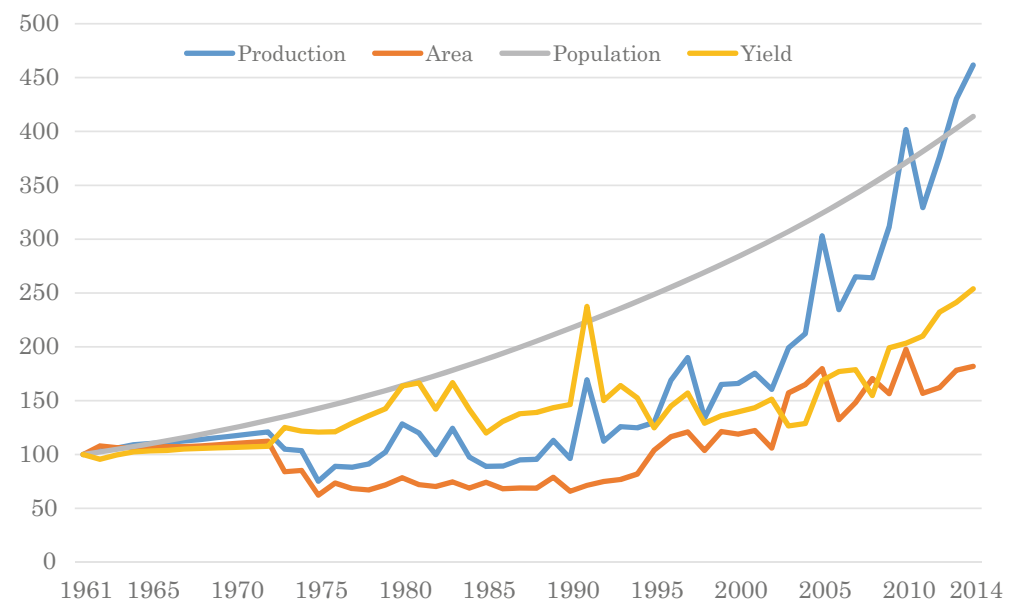

Fig. 2.7 Changes in grain production, harvested area, population, and grain yield in SSA (Index: $1961=100)$. Source FAOSTAT (2016)

because of the increase in cultivated area, but more importantly because of the rapid yield growth.

Such yield growth seems consistent with the arguments of Boserup (1965) and Hayami and Ruttan (1985). The question is whether it can be interpreted as an indicator of a nascent African Green Revolution. For this purpose, it is instructive to compare the yields of individual crops in SSA with those in India, a beneficiary of 


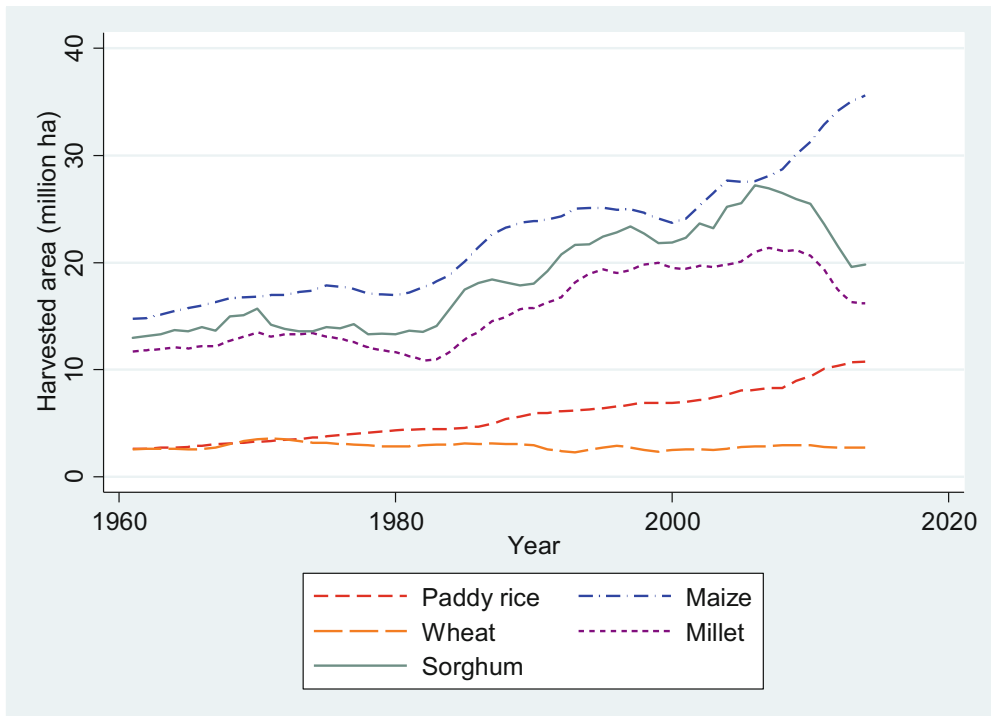

Fig. 2.8 Changes in aggregate harvested area in SSA by major crop. Source FAOSTAT (2016)

the Green Revolution in rice and wheat, whose agro-climate is relatively similar to that in SSA among the Asian countries. ${ }^{14}$

Before comparing the trends of individual grain yields, it would be useful to examine the relative importance of different grains in terms of harvested area (Fig. 2.8). Maize is by far the most important grain in SSA, whose harvested area has been expanding rapidly. Sorghum and millet are less and roughly equally important compared to maize, but their harvested areas have been declining in tandem during the past decade. Since their yields are comparatively low and stagnant, ${ }^{15}$ harvested areas would have been replaced by maize areas. Rice harvested area has been much smaller, but it is steadily increasing primarily due to the conversion of uncultivated marshy land to lowland paddy fields. The importance of wheat is much lower, and its area has been largely constant because it can be grown only in cool climates, found primarily in South Africa and the highlands of eastern Africa. In the following, I focus on the analysis of rice and maize yields in SSA compared to those in India because these crops are more promising than other grains.

There are several important observations derived from the comparison of average rice yields in SSA with the yields of top and bottom 10 countries within SSA plus

\footnotetext{
${ }^{14}$ The major conclusions remain the same qualitatively, even if average yield in tropical Asia was used.

${ }^{15}$ Although not shown here, the yields of sorghum and millet are not only low and stagnant in both SSA and Asia but also similar between the two, indicating the Green Revolution of these crops did not take place in tropical Asia or SSA so far (Otsuka and Muraoka 2017).
} 


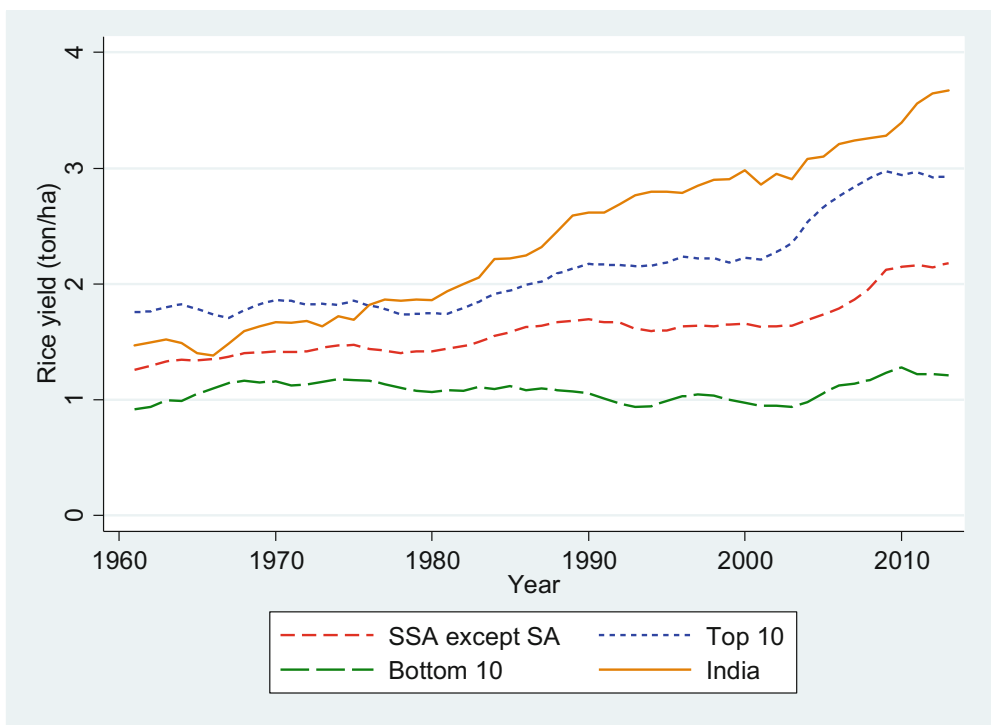

Fig. 2.9 Changes in average rice yield in SSA, top 10 and bottom 10 countries, and India. Source FAOSTAT (2016)

India (Fig. 2.9) ${ }^{16}$ First, the average yield gap between SSA and India was small in the 1960s, refuting the often-held view that crop yield is higher in Asia due to more favorable climates. According to Nakano and Otsuka (2011), paddy yield was 3 tons per hectare in the Doho Irrigation Scheme in Uganda, even though no chemical fertilizers were applied, and double cropping had been practiced for more than two decades. Nakano et al. (2018a) report that rice yield is as high as 5 tons per hectare even in rainfed conditions in Kilombero Valley in Tanzania if proper cultivation practices are applied. These findings indicate that both agro-climate and soil conditions are favorable for lowland rice production, at least in some areas of Uganda and Tanzania. Although I cannot generalize these findings to the entire SSA, the literature review by Balasubramanian et al. (2007) concludes that rice yield potential in SSA is high. Furthermore, according to my own field observations, many rainfed paddy fields are located in valley bottoms in SSA, which are moist and fertile and, hence, favorable for rice production.

Second, rice yield began increasing in India by the late 1960s, although the improved rice varieties adopted in India at that time had been developed in the Philippines, such as IR8. Therefore, the early takeoff of rice yields in India suggests a high transferability of improved modern rice varieties from Southeast Asia to South Asia. Additionally, irrigation investments were induced in Asia, as the rate of return on such investments increased with the introduction of MVs (Hayami and

\footnotetext{
${ }^{16}$ Rice includes both lowland and upland rice, the latter accounting for nearly $40 \%$ of the total rice area. While the yield of upland rice is generally low, new upland varieties, called NERICA, are high yielding in some areas in SSA (e.g., Uganda; Kijima et al. 2011).
} 
Kikuchi 1978). Chapter 10 reports that the irrigation ratio in Asia increased from $20 \%$ in 1965 to $45 \%$ in 2015 (see Fig. 10.3). According to my own observations, IRRI varieties and their offspring are widely grown in irrigation schemes across the continent, which also indicates the high transferability of Asian MVs to SSA. Third, the difference in yield between average and top 10 countries is large,${ }^{17}$ which implies paddy yield is considerably higher in the advanced regions in SSA. Indeed, the yield gap between the top 10 countries and India was relatively small, which strongly suggests that improved rice production systems have been successfully adopted at least in advanced areas in SSA. In fact, rice yields are higher than 5 tons per hectare in several irrigated areas in SSA, where MVs and improved management practices were adopted (Otsuka and Larson 2016), and also far higher than average rice yields in tropical Asia (see Fig. 2.4).

Rice yield is significantly higher under irrigated than rainfed conditions in Asia (e.g., David and Otsuka 1994; Otsuka and Hayami 1994) because of the decisive impact of irrigation on rice yield (see Chap. 12). Njeru et al. (2016) point out, based on case-study evidence, that as far as irrigated areas are concerned, there is no significant difference in the relationship between fertilizer application and yield per hectare between tropical Asia and SSA. This suggests that the properties of yield functions are similar between tropical Asia and SSA. However, the fertilizer application per hectare tends to be lower in SSA because real fertilizer priced tend to be higher. Although the irrigated area accounts for only $15 \%$ of the paddy area in SSA (Balasubramanian et al. 2007), Asian rice Green Revolution technologies function well in irrigated rice areas in SSA. Indeed, roughly $50 \%$ of paddy areas in the top 10 countries in SSA are irrigated.

Finally, average rice yield began increasing around 2005, which may indicate that the rice sector in SSA is currently transitioning to the Green Revolution. Indeed, adaptive crop breeding research developed a large number of improved rice varieties in SSA (Yamano et al. 2016).

For comparative purposes, Fig. 2.10 shows the yield trend of maize in SSA and India. First, similar to the case of rice, the yield gap between SSA and India was negligible in the 1960s and 1970s, which indicates either the difference in agroclimate between SSA and India is not a decisive determinant of maize yield or agroclimatic differences are small. Second, the maize yield in India began increasing in the mid-1980s due to the Green Revolution, resulting in a yield gap of roughly 1 ton per hectare between SSA and India in recent years. However, this gap is much smaller than for rice, where the yield gap amounts to two tons per hectare. Since improved maize varieties are highly location specific (Smale et al. 2013), improving the maize yield in SSA seems more difficult than for rice. Third, the difference in yield between the average and top 10 countries in SSA is relatively small, ${ }^{18}$ which indicates the maize yield is low even in the most advanced regions in SSA. Therefore,

\footnotetext{
${ }^{17}$ Note that, although yield in the bottom 10 countries is very low, their harvested areas are relatively small, so that average yield is not significantly affected by the overly low yield.

${ }^{18}$ Note that, although yield in the bottom 10 countries is very low, harvested areas are small so that the average is not significantly affected by the low yield.
} 


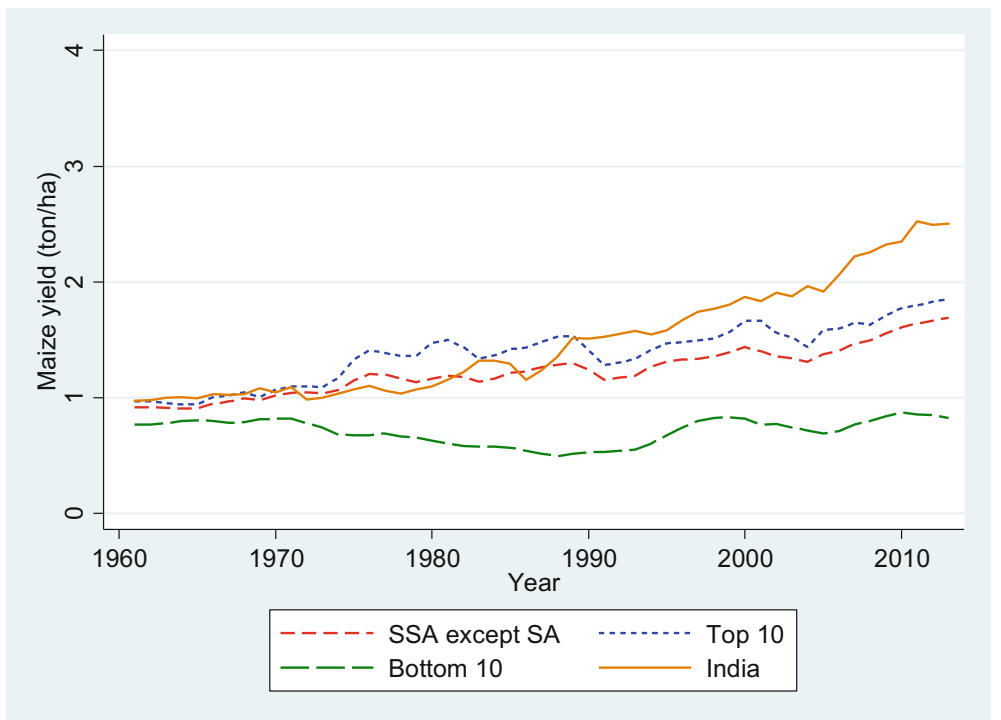

Fig. 2.10 Changes in average maize yields in SSA, top 10 and bottom 10 countries, and India. Source FAOSTAT (2015)

it seems safe to conclude that the maize Green Revolution did not take place on a large scale anywhere in SSA. The lack of adaptive research is likely to be one of the causes for the delay of an African maize Green Revolution. Fourth, similar to the case of rice, the maize yield in SSA began increasing around 2005, which may reflect the increasing adoption of new technologies, possibly leading to a maize Green Revolution in SSA. According to the review of literature on maize production in SSA by Otsuka and Muraoka (2017), the adoption of high-yielding hybrid seeds, use of chemical fertilizer as well as manure and compost, and application of inter-cropping with leguminous crops which have the capacity to fix nitrogen have been gradually increasing in SSA. Furthermore, responding to population pressure, markets have been developing and improved soil management technologies adopted in East Africa (Yamano et al. 2011).

The critical question is whether a full-fledged Green Revolution can take place in SSA and a related question is what its constraints are on this continent. According to Otsuka and Larson $(2013$, 2016), rice is the most promising crop in SSA, primarily because of the high transferability of the Asian Green Revolution technology. This view is consistent with the transfer history of rice technology from Japan to Taiwan, and further to the Philippines and South Asia. A major constraint of the Green Revolution in SSA is low grain prices (see Fig. 2.5), which would discourage farmers' incentives to adopt new technologies and those of researchers to develop them. Declining and small farm size in SSA is not a major concern, because an inverse relationship between farm size and productivity is widely observed in SSA (Larson et al. 2014), indicating that small farms relying on family labor are more 
productive than large farms relying on hired labor. Therefore, the Green Revolution is compatible with smallholder agriculture in SSA (Larson et al. 2016), as was the case in tropical Asia.

In my view, another and more serious constraint is the lack of recognition that the Green Revolution technology is "management intensive." The Green Revolution is alternatively called the "seed-fertilize" revolution in the literature (Johnston and Cownie 1969), which indicates that if improved fertilizer-responsive seeds and chemical fertilizers are adopted, it will take place. However, I believe this is incorrect as not only improved seeds and fertilizers, but also improved management practices, such as seed selection, bunding, leveling, transplanting in row, and weeding are critically important to improving rice yields. This has been proven by assessing the impact of improved management training on rice yield, income, and profit per hectare under both irrigated and rainfed conditions in SSA (deGraft-Johnson et al. 2014; Kijima et al. 2012; Nakano et al. 2018b; Otsuka and Larson 2016; Takahashi et al. 2018). Rice yield seems to increase by $25-50 \%$ if proper management practices are adopted, even if improved seeds and chemical fertilizers are not used. The importance of these improved management practices would not have been emphasized in tropical Asia in the 1960s and 1970s partly because it was considered "trivially" true and also because basic management practices had been adopted in Asia due primarily to its long tradition of rice farming. ${ }^{19}$ The lack of recognition that that Green Revolution is management intensive leads to a lack of effective extension systems. ${ }^{20}$ Consequently, the Green Revolution will not take place widely in SSA, unless and until proper extension systems are built. The failure to accomplish the Green Revolution will delay the evolution of African countries towards an emerging state, as discussed in the next section.

\subsection{Agricultural Development and Paths to an Emerging State}

Following de Janvry and Sadoulet (2002), Otsuka et al. (2009), and Estudillo and Otsuka (2016), Fig. 2.11 illustrates how technological innovations in agriculture and irrigation investment, which lead to the Green Revolution, affect rural household income directly by increasing the efficiency and profitability of farming and indirectly through the growth linkage effects on nonfarm sectors and changes in the prices of agricultural products. ${ }^{21}$ The growth linkage effects of the Green Revolution

\footnotetext{
${ }^{19}$ I obtained this information from the former assistant of IRRI, Violy Cordova, who had worked for IRRI since 1970, Dr. Chukichi Kaneda who worked for IRRI in the early 1970s, and Professor Koji Tanaka of Kyoto University who has researched the history of the development of rice faming in Asia.

${ }^{20}$ This is true not only for rice but also for maize (Otsuka and Muraoka 2017).

${ }^{21}$ For simplicity, Fig. 2.11 does not consider the consumption linkage effect of agricultural innovations on nonfarm sectors, which arises from increases in farm household income. Additionally, the possible effect of human capital on the introduction of new technologies is ignored.
} 


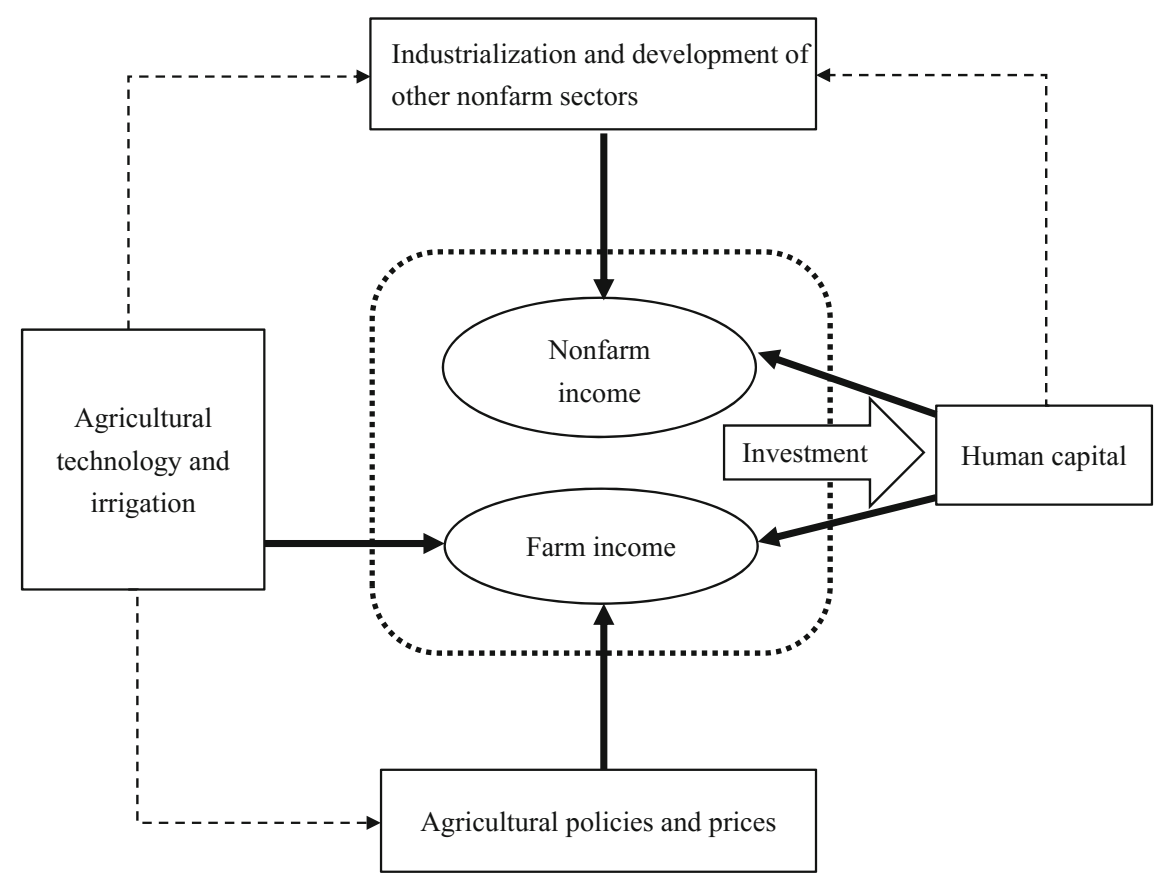

Fig. 2.11 Linkages between agricultural development and industrialization

on the development of nonfarm sectors arise from increased demand for chemical fertilizers and other purchased inputs and from an increased supply of farm products for processing activities. While rigorous estimations of the growth linkage effect are scant, Christiaensen et al. (2011) demonstrate that agricultural growth leads to the growth of the nonfarm economy by employing cross-country regressions. Because of the weak evidence, a dotted line is used for connecting agricultural technology and irrigation with industrial development. The reduction in food prices due to the Green Revolution has negative effects on farm household incomes and also provides negative incentives to generate new agricultural technologies and invest in irrigation. At the same time, lower food price will stimulate industrial development and the development of other nonfarm sectors by reducing the cost of living for urban workers. Another major factor that affects the income of rural households and development of nonfarm sectors is human capital. Schooling, a major component of human capital along with health, is known to affect farming efficiency (e.g., Foster and Rosenzweig 1996) and have a positive effect on the choice of nonfarm jobs and income (e.g., Jolliffe 2004; Matsumoto et al. 2006; Nakajima et al. 2018). An important point is that educational investment is strongly affected by the income of rural households (Estudillo and Otsuka 2016; Otsuka et al. 2009). An educated rural labor force tends to choose nonfarm jobs and thereby further contributes to its development. 
In short, the Green Revolution aids the development of industries and other nonfarm sectors by supplying wage goods and an educated labor force to the extent that the Green Revolution increases the income of rural households and, consequently, stimulates educational investment. The failure of the Green Revolution in SSA may well be one of the major causes for the failure of industrial development and the weak effects of labor allocation from agriculture to other sectors on the labor productivity of African economies, as reported in Chap. 9.

Here, a critical question is the role of the state in promoting the Green Revolution. Since improved varieties are public goods, particularly when they can be reproduced by farmers, the government must play a major role in agricultural research. ${ }^{22}$ Knowledge of improved agronomic practices can thus be shared among farmers in the locality and, hence, it is a local public good. Therefore, the government must take responsibility for agricultural extension. Furthermore, irrigation water is a common pool resource and, thus, the market fails to build irrigation facilities and allocate water efficiently (see Chap. 12 for details). Here too, the state must play a leading role. Therefore, whether the agrarian economy successfully evolves towards an emerging state critically hinges on the government's agricultural policy.

It is noteworthy that the income of a rural household is the major determinant of its investment in human capital (Otsuka et al. 2009). If a Green Revolution takes place, thereby improving farm income and stimulating the development of nonfarm sectors, there can be a virtuous circle of income growth, increased investment in human capital, and the subsequent development of farm and nonfarm sectors. The effects of the Green Revolution and human capital, as well as those of nonfarm sector development on farm household income in Asia and Africa are analyzed in depth in Chap. 10, using primary data.

Chapters 6-8 focus on industrialization in Asia, whereas Chap. 9 examines how industrialization can be promoted by policy means in SSA. A common finding is the importance of labor-intensive industrialization, particularly during the early stages of economic development. Although agricultural development can contribute to industrialization by supplying an educated labor force and cheap foods, its contribution is often curtailed by insufficient and inefficient extension systems, as pointed out in this chapter, and inappropriate irrigation policies, which will be discussed in Chap. 12. Particularly, the efficient management of ground water is extremely difficult because of the free access to this source of irrigation water. Practically, the most effective system is community irrigation because people know each other very well within a community and punishment on deviating behavior from the communal agreement is feasible and possibly severe. Chapter 12, which concerns irrigation management, demonstrates that insufficient or improper recognition of the importance of community irrigation systems by the government leads to mismanagement of irrigation water, which in turn, deters agricultural development.

\footnotetext{
${ }^{22}$ To the extent that improved varieties can be diffused across country borders, they are "global" or "regional" public goods. That is why international organizations, such as IRRI, undertake agricultural research.
} 
The Green Revolution in Asia contributed to a reduction in grain prices, which must have reduced farm household income directly. Indirectly, lower food prices stimulate the development of nonfarm sectors, which creates nonfarm job opportunities for rural households. Furthermore, the governments of developing countries tend to "exploit" agriculture by intentionally reducing product prices and increasing input prices (e.g., by imposing export tax on agricultural products and import tariffs on imported agricultural inputs). Such policies reduce the incentives to realize a Green Revolution. On the other hand, to reduce the income gap between farm and nonfarm sectors, the governments of developed countries tend to "protect" agriculture by price support, input subsidies, and import restrictions. Such policies stimulate domestic production in developed countries excessively and reduce agricultural product prices internationally, thereby discouraging the agricultural development in developing countries. Chapter 11 examines whether the "development paradox" of exploiting agriculture in developing countries applies to Africa.

To sum up, based on the analysis of the evolutionary process of the Green Revolution in this chapter, Chaps. 10-12 attempt to identify the determinants of agricultural development, which will eventually contribute to guiding developing economies towards an emerging state.

\section{References}

Balasubramanian, V., Sie, M., Hijmans, R. J., \& Otsuka, K. (2007). Increasing rice production in sub-Saharan Africa: Challenges and opportunities. Advancement in Agronomy, 94(6), 55-133.

Barker, R., \& Herdt, R. (1985). The Asian rice economy. Baltimore: Johns Hopkins University Press.

Boserup, E. (1965). The conditions of agricultural growth: The economics of agrarian change under population pressure. London: George Allen and Unwin.

Christiaensen, L., Demery, L., \& Kuhl, J. (2011). The (evolving) role of agriculture in poverty reduction: An empirical perspective. Journal of Development Economics, 96(2), 239-254.

David, C. C., \& Otsuka, K. (1994). Modern rice technology and income distribution in Asia. Boulder: Lynne Rienner.

Dalrymple, D. G. (1986). Development and spread of high-yielding rice varieties in developing countries. Washington, DC: Agency for International Development.

deGraft-Johnson, M., Suzuki, A., Sakurai, T., \& Otsuka, K. (2014). On the transferability of the Asian rice green revolution to rainfed areas in sub-Saharan Africa: An assessment of technology intervention in Northern Ghana. Agricultural Economics, 45(5), 555-570.

de Janvry, A., \& Sadoulet, E. (2002). World poverty and role of agricultural technology: Direct and indirect effects. Journal of Development Studies, 38(4), 1-26.

Estudillo, J. P., \& Otsuka, K. (2016). Moving out of poverty: An inquiry into inclusive growth in Asia. London, UK: Routledge.

Foster, A., \& Rosenzweig, M. R. (1996). Technical change and human capital returns and investment: Evidence from the Green Revolution. American Economic Review, 86(4), 931-953.

Hayami, Y., \& Godo, Y. (2005). Development economics: From the poverty to the wealth of nations. New York: Oxford University Press.

Hayami, Y., \& Kikuchi, M. (1978). Investment inducements to public infrastructure: Irrigation in the Philippines. Review of Economics and Statistics, 60(1), 70-77. 
Hayami, Y., \& Ruttan, V. W. (1985). Agricultural development: An international perspective. Baltimore: Johns Hopkins University Press.

Hsieh, S. C., \& Ruttan, V. W. (1967). Environmental, technological, and institutional factors in the growth of rice production: Philippines, Thailand, and Taiwan. Food Research Institute Studies, 7, 307-341.

Janaiah, A., Hossain, M., \& Otsuka, K. (2005). Is the productivity impact of the Green Revolution in rice vanishing? Economic and Political Weekly, 40(53), 5596-5600.

Jolliffe, D. (2004). The impact of education in rural Ghana: Examining household labor allocation and returns on and off farm. Journal of Development Economics, 73(1), 287-314.

Johnston, B. F., \& Cownie, J. (1969). The seed-fertilizer revolution and labor force absorption. American Economic Review, 59(4), 569-582.

Kijima, Y., Ito, N., \& Otsuka, K. (2012). Assessing the impact of training on lowland rice productivity in an African setting: Evidence from Uganda. World Development, 40(8), 1619-1633.

Kijima, Y., Otsuka, K., \& Sserunkuuma, D. (2011). An inquiry into constraints on a green revolution in sub-Saharan Africa: The case of NERICA rice in Uganda. World Development, 39(1), 77-86.

Larson, D., Otsuka, K., Matsumoto, T., \& Kilic, T. (2014). Should African rural development strategies depend on small farms? An exploration of the inverse productivity Hypothesis. Agricultural Economics, 45(3), 355-367.

Larson, D., Muraoka, R., \& Otsuka, K. (2016). Why African rural development strategies must depend on small farms. Global Food Security, 10, 39-51.

Matsumoto, T., Kijima, Y., \& Yamano, T. (2006). The role of local nonfarm activities and migration in reducing poverty: Evidence from Ethiopia, Kenya, and Uganda. Agricultural Economics, 35(S3), 449-458.

Meadows, D. H., Meadows, D. L., Randes, J., \& Behrens, W. W. (1972). The limits to growth. New York: Universe Books.

Nakajima, M., Yamano, T., \& Otsuka, K. (2018). Jobs off the farm: Wealth, human capital, and social groups in rural eastern India. Journal of Development Studies, 54(1), 111-132.

Nakano, Y., \& Otsuka, K. (2011). Determinants of household contributions to collective irrigation management: A case of the Doho rice scheme in Uganda. Environment and Development Economics, 16(5), 521-551.

Nakano, Y., Tanaka, Y., \& Otsuka, K. (2018a). Impact of training on the intensification of rice farming: Evidence from rain-fed areas in Tanzania. Agricultural Economics, 49(2), 193-202.

Nakano, Y., Tsusaka, T. W., Aida, T., \& Pede, V. O. (2018b, forthcoming). Is farmer-to-farmer extension effective? The impact of training on technology adoption and rice farming productivity in Tanzania. World Development, 105, 336-351.

Njeru, T., Mano, Y., \& Otsuka, K. (2016). Role of access to credit in rice production in sub-Saharan Africa: The case of Mwea irrigation scheme in Kenya. Journal of African Economies, 25(2), $300-321$.

Otsuka, K. (2013). Food insecurity, income inequality, and the changing comparative advantage in world agriculture. Agricultural Economics, 44(S1), 7-18.

Otsuka, K., Estudillo, J. P., \& Sawada, Y. (Eds.). (2009). Rural poverty and income dynamics in Asia and Africa. London, UK: Routledge.

Otsuka, K., \& Hayami, Y. (1994). Beyond the green revolution: agricultural development strategy into the new century. In J. Anderson (Ed.), Agricultural technology: Policy issues for the international community (pp. 15-42). Wallingford: CAB International.

Otsuka, K., \& Larson, D. (Eds.). (2013). An African Green Revolution: Finding ways to boost productivity on small farms. Dordrecht: Springer.

Otsuka, K., \& Larson, D. (Eds.). (2016). In pursuit of an African Green Revolution: Views from rice and maize farmers' fields. Dordrecht: Springer.

Otsuka, K., \& Muraoka, R. (2017). A green revolution for sub-Saharan Africa: Past failures and future prospects. Journal of African Economies, 26(S1), i73-i98. 
Smale, M., Byerlee, D., \& Jayne, T. (2013). Maize revolution in sub-Saharan Africa. In K. Otsuka \& D. Larson (Eds.), An African Green Revolution: Finding ways to boost productivity on small farms (pp. 165-195). Dordrecht: Springer.

Tanaka, K. (2012). Seizon kiban jizokugara hatten keiro o motomete: Ajia inasakuken no keiken kara (In search of sustainable livelihood system: a view from the experience of rice growing areas in Asia). In K. Sugihara, K. Wakimura, K. Fujita, \& A. Tanabe A (Eds.), Rekishi no nakano nettai seizon ken (Livelihood space in history of tropics) (pp. 185-210). Kyoto: Kyoto University Press.

Tanaka, K., \& Imai, R. (2006). Shokuminchi keiei to nogyo gujutu: Taiwan, Nanpo, Manshu (Management of colonies and agricultural technology: Taiwan, Tropics, and Manchuria). In K. Tanaka (Ed.), Teikoku Nihon no Gakuchi (Wisdom of the Empire Japan) (pp. 100-137). Tokyo: Iwanami Shoten.

Takahashi, K., Mano, Y., \& Otsuka, K. (2018). Beyond the SUTVA: The dynamic impact of management training and subsequent information spillover on agricultural performance in Cote d'Ivoire. Mimeographed.

Umemura, M., Yamada, S., Hayami, Y., Takamatsu, M., \& Kumazki, M. (1966). Estimates of long-term statistics of Japan since 1868: Agriculture and forestry. Tokyo, Japan: Toyo Keizai Shinposha.

Yamano, T., Arouna, A., Labarta, R. A., Huelgas, Z. M., \& Mohanty, S. (2016). Adoption and impacts of international rice research technologies. Global Food Security, 8, 1-8.

Yamano, T., Otsuka, K., \& Place, F. (Eds.). (2011). Emerging development of agriculture in East Africa: Markets, soil, and innovations. Amsterdam: Springer.

Open Access This chapter is licensed under the terms of the Creative Commons AttributionNonCommercial-NoDerivatives 4.0 International License (http://creativecommons.org/licenses/bync-nd/4.0/), which permits any noncommercial use, sharing, distribution and reproduction in any medium or format, as long as you give appropriate credit to the original author(s) and the source, provide a link to the Creative Commons licence and indicate if you modified the licensed material. You do not have permission under this licence to share adapted material derived from this chapter or parts of it.

The images or other third party material in this chapter are included in the chapter's Creative Commons licence, unless indicated otherwise in a credit line to the material. If material is not included in the chapter's Creative Commons licence and your intended use is not permitted by statutory regulation or exceeds the permitted use, you will need to obtain permission directly from the copyright holder.

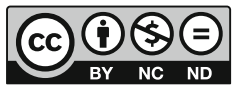

